\title{
Regulation of energy homeostasis via GPR120
}

\author{
Atsuhiko Ichimura ${ }^{1}$, Takafumi Hara ${ }^{2}$ and Akira Hirasawa ${ }^{2}$ \\ 1 Department of Molecular Medicine and Therapy, Tohoku University Graduate School of Medicine, Sendai, Japan \\ 2 Department of Pharmacogenomics, Graduate School of Pharmaceutical Sciences, Kyoto University, Kyoto, Japan
}

\section{Edited by:}

Ikuo Kimura, Tokyo University of

Agriculture and Technology, Japan

\section{Reviewed by:}

Alexandra Proshchina, Russian

Academy of Medical Sciences, Russia

Zhong Q. Wang, Pennington

Biomedical Research Center, USA

*Correspondence:

Atsuhiko Ichimura, Department of Molecular Medicine and Therapy,

Tohoku University Graduate School of Medicine, 2-1 Seiryo-cho, Aoba-ku,

Sendai 980-8575, Japan

e-mail: aichimura@med.tohoku.ac.jp
Free fatty acids (FFAs) are fundamental units of key nutrients. FFAs exert various biological functions, depending on the chain length and degree of desaturation. Recent studies have shown that several FFAs act as ligands of G-protein-coupled receptors (GPCRs), activate intracellular signaling and exert physiological functions via these GPCRs. GPR120 (also known as free fatty acid receptor 4 ) is activated by unsaturated medium- to long-chain FFAs and has a critical role in various physiological homeostasis mechanisms such as incretin hormone secretion, food preference, anti-inflammation, and adipogenesis. Recent studies showed that a lipid sensor GPR120 has a key role in sensing dietary fat in white adipose tissue and regulates the whole body energy homeostasis in both humans and rodents. Genetic study in human identified the loss-of-functional mutation of GPR120 associated with obesity and insulin resistance. In addition, dysfunction of GPR120 has been linked as a novel risk factor for diet-induced obesity. This review aims to provide evidence from the recent development in physiological function of GPR120 and discusses its functional roles in the regulation of energy homeostasis and its potential as drug targets.

Keywords: GPR120, FFAR4, FFAs, metabolic syndrome, diabetes mellitus

\section{INTRODUCTION}

Free fatty acids (FFAs) are basic components of biological structures, precursors of various mediators, and play important roles as essential nutrients (1). During the past decade, however, a number of studies revealed that FFAs also act as key signaling molecules to regulate a number of physiological functions through G-proteincoupled receptors (GPCRs) (1-4). The superfamily of GPCRs includes at least 800 seven-transmembrane receptors that have diverse physiological and pathological functions. GPCRs are the most successful targets of drug (5). Of interest, FFAs act as ligands of some GPCRs. FFAs can be classified depending on their chain length as short-chain fatty acids (SCFAs), which have 1-6 carbon chain length; medium-chain fatty acids (MCFAs, 7-12 carbon chain length); and long-chain fatty acids (LCFAs), which have more than 12 carbon chain length. Some of non-esterified FFAs directly regulate important biological processes such as energy homeostasis via their corresponding receptors $(6-10)$. The LCFA receptor GPR40 (also known as FFAR1), SCFA receptors GPR41 (FFAR3) and GPR43 (FFAR2) were identified in 2003 (11-18). In 2005, we successfully deorphanized and identified GPR120 [also known as free fatty acid receptor 4 (FFAR4)] as a FFAs receptor (FFARs), which is activated by unsaturated MCFAs and LCFAs (19). These GPCRs are widely expressed in the body and contribute to maintain systemic energy homeostasis under changing nutritional conditions. Among these FFARs, GPR120 emerged as an important checkpoint in regulating energy homeostasis $(6,8)$. Previous studies also showed that GPR120 has been implicated in several key processes including the release of incretin hormone, anti-inflammation, food preference, glucose homeostasis, insulin sensitivity, and adipogenesis $(6,8,19-24)$. These factors interrelate to regulate systemic metabolic energy and nutritional homeostasis under physiological and pathophysiological conditions. Hence, in this review, we attempt to summarize and discuss the recent advances in research regarding the roles of GPR120.

\section{TISSUE DISTRIBUTION OF GPR120}

GPR120 is widely expressed in various tissues and cell types including intestine, macrophages, adipose tissue, taste buds, brain, pancreas, lung, thymus, and pituitary $(2,6,8)$. Hence, GPR 120 has multiple functions in homeostatic regulation of systemic metabolism and inflammation depending on this diverse tissue distribution. Furthermore, GPR120 is co-localized with not only glucagon-like peptide 1 (GLP-1) in the colon and circumvallate papillae taste bud cells $(19,25,26)$, but also with ghrelin (27) and $\alpha$-gustducin in the duodenum and type II taste bud cells, respectively $(28,29)$. GPR120 was also reported to be coexpressed with other FFARs, such as GPR40 in STC-1 intestinal cells (19) and GPR43 in the proximal colon in mice (29). These characteristics of expression patterns and co-localization might reflect the physiological functions of GPR120 as described below.

\section{INTESTINE}

GPR120 is expressed in the intestines of humans as well as mice. Furthermore, the enteroendocrine cell line STC-1 also expressed GPR120 endogenously. We have previously shown that GLP-1expressing enteroendocrine cells in the colon were expressing GPR120 in both rodents and human $(19,20,25)$. Secretion of GLP-1 and cholecystokinin (CCK), both known as incretin hormones and involved in the regulation of feeding behaviors, energy metabolism and bodyweight (30-32), was induced by FFAs stimulation from enteroendocrine STC-1 cells (33). The administration of FFAs into the murine colon stimulated GLP- 1 secretion and increased plasma level of insulin (19). Furthermore, we have 
found that the knockdown of GPR120 expression by siRNA inhibited the FFAs-induced $\left[\mathrm{Ca}^{2+}\right]_{\mathrm{i}}$ response and incretin hormones secretion in STC-1 cells. These data highly suggested that GPR120 indeed mediate and stimulate incretin hormone secretion in vivo. In addition, $\mathrm{K}$ cells, which are found in the mucosa of the duodenum and the jejunum of the gastrointestinal tract and also synthesize gastric inhibitory peptide (GIP), also express GPR120 (34). Interestingly, recent reports indicated that GPR120 was co-localized with the orexigenic peptide, ghrelin in duodenal cells in vivo, and FFAs stimulation reduced ghrelin secretion in the MGN31 ghrelinoma cell line (35). Furthermore, Gong et al. revealed that addition of GW-9508, a GPR120 chemical agonist, inhibited the secretion of ghrelin from ghrelin-producing stomach ghrelinoma (SG-1) cells. They also showed that SG-1 cells highly expressed GPR120 endogenously and the inhibitory effect of GW-9508 on ghrelin secretion was blocked by siRNA against GPR120 in SG-1 cells. Furthermore, GW-9508 treatment reduced plasma ghrelin level in vivo (36). These reports indicate that the decrease of postprandial ghrelin is induced at least partially by LCFAs included in foods via GPR120. Given the effects on GLP-1, CCK, and ghrelin secretion, the stimulation of GPR120 might regulate appetite and systemic energy homeostasis.

\section{MACROPHAGES}

GPR120 was found to be expressed in monocytic RAW267.4 cells and primary proinflammatory M1-like macrophages (6). The activation of GPR120 by $\omega$-3 LCFAs, such as docosahexaenoic acid (DHA) and alpha-linolenic acid ( $\alpha$-LA), exerts broad of anti-inflammatory effects in these cells, all of which were abolished by siRNA against GPR120. These $\omega-3$ LCFAs are identified as anti-inflammatory fatty acids in the tissue-specific and systemic levels (9). Oh et al. clearly showed that $\omega$-3 LCFAs exert anti-inflammatory effects through GPR120. In vitro experiments revealed the molecular mechanism underlying $\omega-3$ FFAsmediated anti-inflammatory effects. Stimulation of GPR120 by $\omega$-3 LCFAs abolished lipopolysaccharide (LPS)-induced phosphorylation and activation of IкB kinase (IKK) and c-Jun $\mathrm{N}$ terminal kinase (JNK) in macrophages. Recruitment of $\beta$-arrestin 2 ( $\beta$-arr2) and following the GPR120- $\beta$-arr2 complex internalization is induced by the activation of GPR120. Tumor necrosis factor- $\alpha$ (TNF- $\alpha)$ and toll-like receptor 4 (TLR4) widely mediate proinflammatory cascades. In addition, tumor growth factor $\beta$ (TGF- $\beta$ ) activated kinase 1 (TAK1) interacting with TGF- $\beta$ activated kinase 1 binding protein 1 (TAB1) mediate downstream inflammatory effects via activation of NF- $\kappa \mathrm{B}$ and JNK. The internalized GPR120- $\beta$-arr 2 complex interacts with TAB1 and inhibits the interaction between TAB1 and TAK1, leading to the inhibition of the downstream proinflammatory pathways. Further in vivo experiments demonstrated that administration of $\omega$ 3 FFAs ameliorated tissue inflammation and thereby improved systemic insulin sensitivity in wild type (WT) mice. The gene deficiency of GPR120 abolished these effects of $\omega$-3 FFAs (6, 9, 37). These results showed that the activation of GPR120 by $\omega-3$ FFAs exerts potent insulin sensitizing and anti-diabetic effects in vivo by the repression of macrophage-induced tissue inflammation.

\section{ADIPOSE TISSUE}

GPR120 was also found to be expressing endogenously in adipocyte and adipose tissue, but not detected in pre-adipocyte $(8,22)$. Furthermore, GPR120 expression was increased according to the lipid accumulation in the cells during induction of adipocyte differentiation in 3T3-L1 cells (22). Knockdown and gene deficiency of GPR120 by siRNA suppressed the expression of adipogenic genes and lipid accumulation in 3T3-L1 cells and mouse embryonic fibroblast, respectively $(8,22)$. These data indicated that GPR120 might be an adipogenic receptor and might play important roles in adipocyte differentiation and maturation. GPR120 mRNA expression was increased in subcutaneous, epididymal, and mesenteric adipose tissue of high fat diet (HFD)-fed mice (22). Moreover, we have shown that GPR120 expression in human adipose tissue was significantly higher in obese individuals than in lean controls (8), suggesting that the expression of GPR 120 could be enhanced by the accumulation of dietary lipid in both rodent and human. Our previous study revealed that GPR120-deficient mice fed HFD developed obesity, which was accompanied with decreased differentiation and lipogenesis in adipocyte. Furthermore, severe fatty liver, enhanced hepatic lipogenesis, increased fasting glucose, and impaired responses to insulin and glucose tolerance were observed in HFD-fed GPR120deficient mice. Gene expression analysis in adipose tissue and liver revealed the molecular basis underlying obesity and insulin resistance of GPR120-deficient mice. Our data showed that HFD-fed GPR120-deficient mice showed a significantly decreased expression of adipogenic gene Fabp4 as well as the key lipogenic gene Scd1. In addition, macrophage marker genes were also increased in adipose tissue, an indication of adipose tissue inflammation. In the liver, on the other hand, the key lipogenic gene Scd1 expression was significantly increased. Insulin signaling-related genes were significantly decreased in both adipose tissue and the liver of HFD-fed GPR120-deficient mice. Furthermore, phosphorylation of IR $\beta$ and IRS1 in white adipose tissues and IRS1 and IRS2 in the liver, all of which are regulators of insulin-stimulated glucose uptake, were significantly decreased. In addition, Oh et al. reported that GPR120 induced a translocation of glucose transporter 4 in 3T3-L1 adipocytes and directly increased glucose uptake (6). Taking together, these data demonstrated that GPR120 acts as a lipid sensor in vivo and plays a critical role in sensing dietary fat to regulate glucose and lipid metabolism.

\section{TASTE BUDS}

Recent studies strongly suggested that oral perception of dietary fat was involved in the detection of taste, in addition to texture and olfaction, of LCFAs (38). GPR120 was reported to be expressed in taste bud type II cells (28). Matsumura et al. showed the colocalization of GPR120 with phospholipase-C $\beta 2$ and $\alpha$-gustducin in the taste buds by double immunostaining. Cartoni et al. further showed the expression of GPR120 in circumvallate papillae (CV) sections by immunohistochemical analysis (39). Short-access test using a lick meter showed that gene deficiency of GPR120 abolished the preference for fatty acids but not for other tastes. These data suggest that the upregulation of GPR120 in the taste buds could induce an excess intake of lipid, leading to obesity. Martin et al. also reported that GPR120 and GLP-1 were found to 


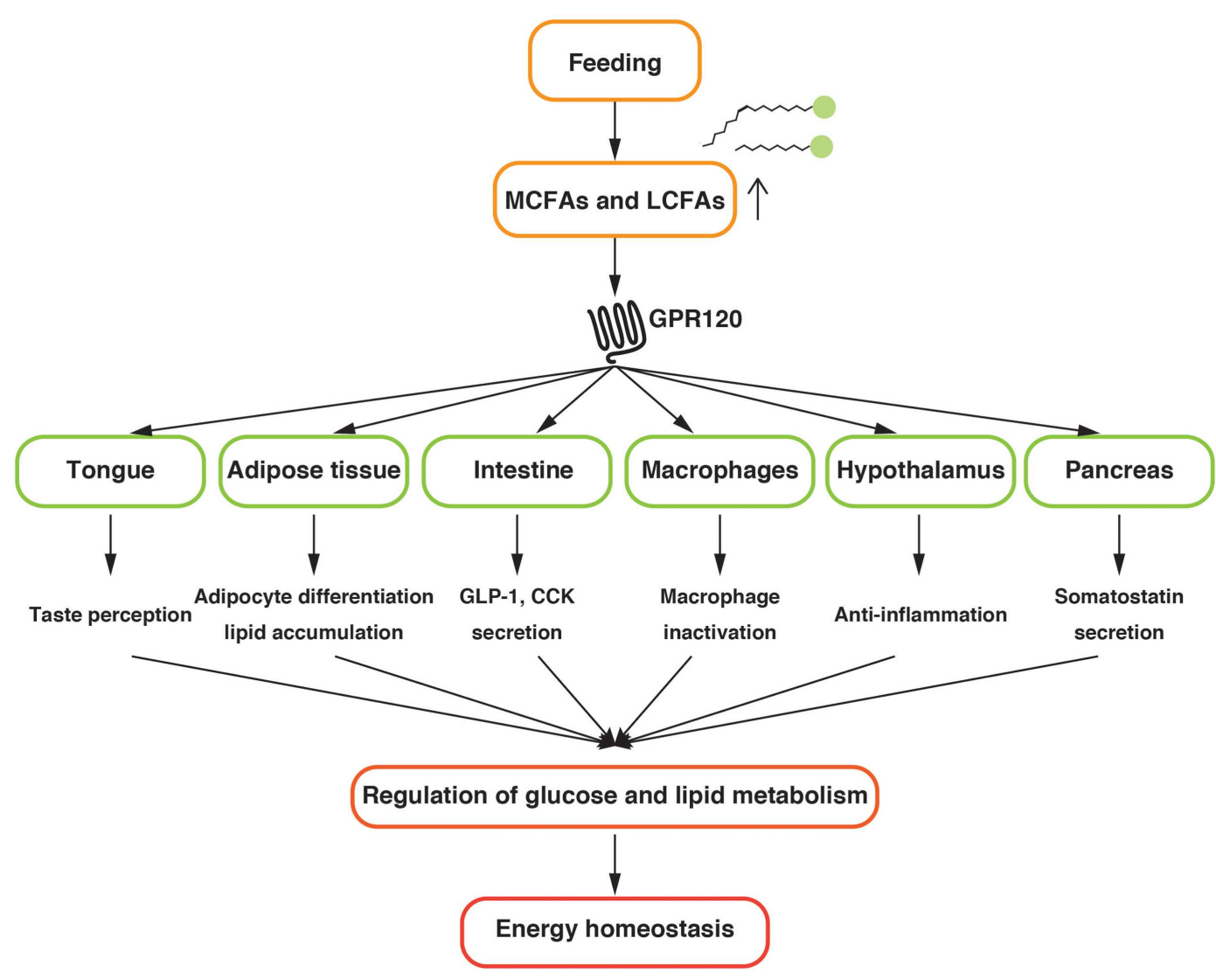

FIGURE 1 | Schematic diagram of the physiological function of GPR120 related to the energy homeostasis.

be co-localized in mouse taste cells from mouse CV (26). Studies using GPR120 selective agonist and isolated mouse CV indicated that GPR120 might be responsible for LCFAs-mediated release of GLP-1 from CVs and might thus contribute to the high palatability of foods rich in both fats and sugars. A recent study further showed that human primary taste bud cells were expressing GPR120 (40). High concentrations of linoleic acid induced $\left[\mathrm{Ca}^{2+}\right]_{i}$ signaling via GPR120 and CD36 in human and mice primary taste bud cells. These reports strongly suggested that GPR120 expressed in taste buds plays an important role in sensing fat taste, contributing to the food intake.

\section{OTHER TISSUES}

GPR120 is also expressed in other tissues and cells. Cintra et al. performed immunostaining analysis and found that GPR120 colocalized with neuropeptide $\mathrm{Y}$ centrally in the arcuate nucleus (41). An acute injection of $\omega-3$ and $\omega-9$ FFAs-induced GPR120$\beta$-arr 2 complex and $\beta$-arr2-TAB1 complex as well as inhibited the interaction between $\mathrm{TAB} 1$ and $\mathrm{TAK} 1$, leading to the reduction of the downstream proinflammatory pathways in the hypothalamus. Furthermore, Wellhauser et al. analyzed the molecular mechanisms to modulate hypothalamic function via GPR120 in vitro using a hypothalamic neuronal model, rHypoE-7 cells, isolated from the rat. They showed that the anti-inflammatory effect of DHA was significantly reduced by siRNA against GPR120 in
rHypoE-7 cells (42). Numbers of studies showed inflammatory response in the hypothalamus in reaction to excessive nutrients contributes to diet-induced obesity and type 2 diabetes mellitus (43-45). Hence, the anti-inflammatory effect mediated by GPR120 in hypothalamus might play an important role in the regulation of systemic energy homeostasis.

Recently, Xhao et al. showed mRNA and protein expression of GPR120 in human and rat pancreas (46). Immunohistological analysis demonstrated that GPR120 is co-localized with CD68, the specific marker of macrophages, and with CD34 and CD117, the markers of interstitial cells in the pancreas. Furthermore, Stone et al. generated Gpr120-knockout/ $\beta$-galactosidase knock-in mice and showed the distribution of GPR120 (23). Immunofluorescence analysis demonstrated the co-localization of GPR120 with somatostatin, suggesting that GPR120 is selectively expressed in islet delta cells. They also demonstrated that treatment of GPR120 selective antagonist inhibited glucose induced somatostatin secretion from isolated islet. Additionally, GPR120-deficiency abolished this effect. Hence, GPR120 expressed in pancreatic delta cells might regulate somatostatin secretion. Further studies are required in order to reveal the functional roles of GPR120 in pancreas.

\section{GENETIC CONTRIBUTION TO TYPE 2 DIABETES}

We previously reported two non-synonymous mutation p.R270H and p.R67C by exon sequencing of GPR120 in obese and lean 
European subjects. Following in vitro experiments revealed that the p.R270H mutant, which significantly associated with obesity, lacked the ability to transduce LCFAs signal, contrary to the p.R67C mutant, which was not associate with obesity. Taken together these human and GPR120-deficient mice, the dysfunction of GPR120 leads to obesity in both mice and human (8). In addition, the systems genomics approach to identify genes for type 2 diabetes showed that GPR120 was placed in the top 16 of the ranked list (47). Taneera et al. reported that GPR120 expression in human islets was positively correlated with both secretion and contents of insulin as well as lower HbA1c levels. These data suggested that GPR120 might have a protective role on human islet.

\section{CONCLUSION}

GPR120 regulates the metabolic homeostasis by sensing LCFAs provided by dietary fat in several tissues (Figure 1). Further investigations to uncover the precise physiological functions of GPR120 are mandatory for a better understanding of systemic nutrient metabolism and energy homeostasis. The current studies suggest that GPR120 activation might have positive outcomes on health. Hence, GPR120 might be a promising pharmaceutical target for the treatment of metabolic diseases.

\section{ACKNOWLEDGMENTS}

This work was supported by Grant-in-Aid for Grant-in-Aid for Young Scientists (B) (to Atsuhiko Ichimura, 25860185) from the Japan Society for the Promotion of Science (JSPS).

\section{REFERENCES}

1. Offermanns S. Free fatty acid (FFA) and hydroxy carboxylic acid (HCA) receptors. Annu Rev Pharmacol Toxicol (2014) 54:407-34. doi:10.1146/annurevpharmtox-011613-135945

2. Ichimura A, Hirasawa A, Hara T, Tsujimoto G. Free fatty acid receptors act as nutrient sensors to regulate energy homeostasis. Prostaglandins Other Lipid Mediat (2009) 89(3-4):82-8. doi:10.1016/j.prostaglandins.2009.05.003

3. Cornall LM, Mathai ML, Hryciw DH, McAinch AJ. GPR120 agonism as a countermeasure against metabolic diseases. Drug Discov Today (2013) 19(5):670-9. doi:10.1016/j.drudis.2013.11.021

4. Hara T, Kashihara D, Ichimura A, Kimura I, Tsujimoto G, Hirasawa A. Role of free fatty acid receptors in the regulation of energy metabolism. Biochim Biophys Acta (2014) 1841(9):1292-300. doi:10.1016/j.bbalip.2014.06.002

5. Tang XL, Wang Y, Li DL, Luo J, Liu MY. Orphan G protein-coupled receptors (GPCRs): biological functions and potential drug targets. Acta Pharmacol Sin (2012) 33(3):363-71. doi:10.1038/aps.2011.210

6. Oh DY, Talukdar S, Bae EJ, Imamura T, Morinaga H, Fan W, et al. GPR120 is an omega-3 fatty acid receptor mediating potent anti-inflammatory and insulin-sensitizing effects. Cell (2010) 142(5):687-98. doi:10.1016/j.cell.2010. 07.041

7. Kimura I, Inoue D, Maeda T, Hara T, Ichimura A, Miyauchi S, et al. Shortchain fatty acids and ketones directly regulate sympathetic nervous system via G protein-coupled receptor 41 (GPR41). Proc Natl Acad Sci U S A (2011) 108(19):8030-5. doi:10.1073/pnas.1016088108

8. Ichimura A, Hirasawa A, Poulain-Godefroy O, Bonnefond A, Hara T, Yengo L, et al. Dysfunction of lipid sensor GPR120 leads to obesity in both mouse and human. Nature (2012) 483(7389):350-4. doi:10.1038/nature10798

9. Oh DY, Olefsky JM. Omega 3 fatty acids and GPR120. Cell Metab (2012) 15(5):564-5. doi:10.1016/j.cmet.2012.04.009

10. Kimura I, Ozawa K, Inoue D, Imamura T, Kimura K, Maeda $T$, et al. The gut microbiota suppresses insulin-mediated fat accumulation via the shortchain fatty acid receptor GPR43. Nat Commun (2013) 4:1829. doi:10.1038/ ncomms 2852

11. Briscoe CP, Tadayyon M, Andrews JL, Benson WG, Chambers JK, Eilert $\mathrm{MM}$, et al. The orphan G protein-coupled receptor GPR40 is activated by medium and long chain fatty acids. J Biol Chem (2003) 278(13):11303-11. doi:10.1074/jbc.M211495200

12. Brown AJ, Goldsworthy SM, Barnes AA, Eilert MM, Tcheang L, Daniels D, et al. The Orphan G protein-coupled receptors GPR41 and GPR43 are activated by propionate and other short chain carboxylic acids. J Biol Chem (2003) 278(13):11312-9. doi:10.1074/jbc.M211609200

13. Itoh Y, Kawamata Y, Harada M, Kobayashi M, Fujii R, Fukusumi S, et al. Free fatty acids regulate insulin secretion from pancreatic beta cells through GPR40. Nature (2003) 422(6928):173-6. doi:10.1038/nature01478

14. Kotarsky K, Nilsson NE, Flodgren E, Owman C, Olde B. A human cell surface receptor activated by free fatty acids and thiazolidinedione drugs. Biochem Biophys Res Commun (2003) 301(2):406-10. doi:10.1016/S0006-291X(02)03064-4

15. Le Poul E, Loison C, Struyf S, Springael JY, Lannoy V, Decobecq ME, et al. Functional characterization of human receptors for short chain fatty acids and their role in polymorphonuclear cell activation. J Biol Chem (2003) 278(28):25481-9. doi:10.1074/jbc.M301403200

16. Nilsson NE, Kotarsky K, Owman C, Olde B. Identification of a free fatty acid receptor, FFA2R, expressed on leukocytes and activated by short-chain fatty acids. Biochem Biophys Res Commun (2003) 303(4):1047-52. doi:10.1016/ S0006-291X(03)00488-1

17. Kimura I, Inoue D, Hirano K, Tsujimoto G. The SCFA receptor GPR43 and energy metabolism. Front Endocrinol (2014) 5:85. doi:10.3389/fendo.2014. 00085

18. Inoue D, Tsujimoto G, Kimura I. Regulation of energy homeostasis by GPR41. Front Endocrinol (2014) 5:81. doi:10.3389/fendo.2014.00081

19. Hirasawa A, Tsumaya K, Awaji T, Katsuma S, Adachi T, Yamada M, et al. Free fatty acids regulate gut incretin glucagon-like peptide-1 secretion through GPR120. Nat Med (2005) 11(1):90-4. doi:10.1038/nm1168

20. Tanaka T, Katsuma S, Adachi T, Koshimizu TA, Hirasawa A, Tsujimoto G. Free fatty acids induce cholecystokinin secretion through GPR120. Naunyn Schmiedebergs Arch Pharmacol (2008) 377(4-6):523-7. doi:10.1007/s00210007-0200-8

21. Tanaka T, Yano T, Adachi T, Koshimizu TA, Hirasawa A, Tsujimoto G. Cloning and characterization of the rat free fatty acid receptor GPR120: in vivo effect of the natural ligand on GLP-1 secretion and proliferation of pancreatic beta cells. Naunyn Schmiedebergs Arch Pharmacol (2008) 377(4-6):515-22. doi:10.1007/s00210-007-0250-y

22. Gotoh C, Hong YH, Iga T, Hishikawa D, Suzuki Y, Song SH, et al. The regulation of adipogenesis through GPR120. Biochem Biophys Res Commun (2007) 354(2):591-7. doi:10.1016/j.bbrc.2007.01.028

23. Stone VM, Dhayal S, Brocklehurst KJ, Lenaghan C, Sorhede Winzell M, Hammar M, et al. GPR120 (FFAR4) is preferentially expressed in pancreatic delta cells and regulates somatostatin secretion from murine islets of Langerhans. Diabetologia (2014) 57(6):1182-91. doi:10.1007/s00125-014-3213-0

24. Hara T, Ichimura A, Hirasawa A. Therapeutic role and ligands of medium- to long-chain fatty acid receptors. Front Endocrinol (2014) 5:83. doi:10.3389/fendo. 2014.00083

25. Miyauchi S, Hirasawa A, Iga T, Liu N, Itsubo C, Sadakane K, et al. Distribution and regulation of protein expression of the free fatty acid receptor GPR120. Naunyn Schmiedebergs Arch Pharmacol (2009) 379(4):427-34. doi:10.1007/s00210-008-0390-8

26. Martin C, Passilly-Degrace P, Chevrot M, Ancel D, Sparks SM, Drucker DJ, et al. Lipid-mediated release of GLP-1 by mouse taste buds from circumvallate papillae: putative involvement of GPR120 and impact on taste sensitivity. J Lipid Res (2012) 53(11):2256-65. doi:10.1194/jlr.M025874

27. Janssen I, Heymsfield SB, Ross R. Low relative skeletal muscle mass (sarcopenia) in older persons is associated with functional impairment and physical disability. J Am Geriatr Soc (2002) 50(5):889-96. doi:10.1046/j.1532-5415.2002. 50216.x

28. Matsumura S, Eguchi A, Mizushige T, Kitabayashi N, Tsuzuki S, Inoue K, et al. Colocalization of GPR120 with phospholipase-Cbeta2 and alpha-gustducin in the taste bud cells in mice. Neurosci Lett (2009) 450(2):186-90. doi:10.1016/j. neulet.2008.11.056

29. Li Y, Kokrashvili Z, Mosinger B, Margolskee RF. Gustducin couples fatty acid receptors to GLP-1 release in colon. Am J Physiol Endocrinol Metab (2013) 304(6):E651-60. doi:10.1152/ajpendo.00471.2012

30. Small CJ, Bloom SR. Gut hormones and the control of appetite. Trends Endocrinol Metab (2004) 15(6):259-63. doi:10.1016/j.tem.2004.06.002 
31. Mendieta-Zeron H, Lopez M, Dieguez C. Gastrointestinal peptides controlling body weight homeostasis. Gen Comp Endocrinol (2008) 155(3):481-95. doi:10.1016/j.ygcen.2007.11.009

32. Flint A, Raben A, Astrup A, Holst JJ. Glucagon-like peptide 1 promotes satiety and suppresses energy intake in humans. J Clin Invest (1998) 101(3):515-20. doi:10.1172/JCI990

33. Sidhu SS, Thompson DG, Warhurst G, Case RM, Benson RS. Fatty acidinduced cholecystokinin secretion and changes in intracellular $\mathrm{Ca} 2+$ in two enteroendocrine cell lines, STC-1 and GLUTag. J Physiol (2000) 528(1):165-76. doi:10.1111/j.1469-7793.2000.00165.x

34. Parker HE, Habib AM, Rogers GJ, Gribble FM, Reimann F. Nutrient-dependent secretion of glucose-dependent insulinotropic polypeptide from primary murine K cells. Diabetologia (2009) 52(2):289-98. doi:10.1007/s00125-0081202-x

35. Janssen S, Laermans J, Iwakura H, Tack J, Depoortere I. Sensing of fatty acids for octanoylation of ghrelin involves a gustatory G-protein. PLoS One (2012) 7(6):e40168. doi:10.1371/journal.pone.0040168

36. Gong Z, Yoshimura M, Aizawa S, Kurotani R, Zigman JM, Sakai T, et al. G protein-coupled receptor 120 signaling regulates ghrelin secretion in vivo and in vitro. Am J Physiol Endocrinol Metab (2014) 306(1):E28-35. doi:10.1152/ ajpendo.00306.2013

37. Talukdar S, Olefsky JM, Osborn O. Targeting GPR120 and other fatty acidsensing GPCRs ameliorates insulin resistance and inflammatory diseases. Trends Pharmacol Sci (2011) 32(9):543-50. doi:10.1016/j.tips.2011.04.004

38. Khan NA, Besnard P. Oro-sensory perception of dietary lipids: new insights into the fat taste transduction. Biochim Biophys Acta (2009) 1791(3):149-55. doi:10.1016/j.bbalip.2009.01.001

39. Cartoni C, Yasumatsu K, Ohkuri T, Shigemura N, Yoshida R, Godinot N, et al. Taste preference for fatty acids is mediated by GPR40 and GPR120. J Neurosci (2010) 30(25):8376-82. doi:10.1523/JNEUROSCI.0496-10.2010

40. Ozdener MH, Subramaniam S, Sundaresan S, Sery O, Hashimoto T, Asakawa Y, et al. CD36- and GPR120-mediated $\mathrm{Ca}(2)(+)$ signaling in human taste bud cells mediates differential responses to fatty acids and is altered in obese mice. Gastroenterology (2014) 146(4):995-1005. doi:10.1053/j.gastro. 2014.01.006

41. Cintra DE, Ropelle ER, Moraes JC, Pauli JR, Morari J, Souza CT, et al. Unsaturated fatty acids revert diet-induced hypothalamic inflammation in obesity. PLoS One (2012) 7(1):e30571. doi:10.1371/journal.pone.0030571
42. Wellhauser L, Belsham DD. Activation of the omega-3 fatty acid receptor GPR120 mediates anti-inflammatory actions in immortalized hypothalamic neurons. J Neuroinflammation (2014) 11:60. doi:10.1186/1742-2094-11-60

43. De Souza CT, Araujo EP, Bordin S, Ashimine R, Zollner RL, Boschero AC, et al. Consumption of a fat-rich diet activates a proinflammatory response and induces insulin resistance in the hypothalamus. Endocrinology (2005) 146(10):4192-9. doi:10.1210/en.2004-1520

44. Milanski M, Degasperi G, Coope A, Morari J, Denis R, Cintra DE, et al. Saturated fatty acids produce an inflammatory response predominantly through the activation of TLR4 signaling in hypothalamus: implications for the pathogenesis of obesity. J Neurosci (2009) 29(2):359-70. doi:10.1523/JNEUROSCI.2760-08. 2009

45. Zhang X, Zhang G, Zhang H, Karin M, Bai H, Cai D. Hypothalamic IKKbeta/NFkappaB and ER stress link overnutrition to energy imbalance and obesity. Cell (2008) 135(1):61-73. doi:10.1016/j.cell.2008.07.043

46. Zhao Y, Zha D, Wang L, Qiao L, Lu L, Mei L, et al. Phenotypic characterization of GPR120-expressing cells in the interstitial tissue of pancreas. Tissue Cell (2013) 45(6):421-7. doi:10.1016/j.tice.2013.07.005

47. Taneera J, Lang S, Sharma A, Fadista J, Zhou Y, Ahlqvist E, et al. A systems genetics approach identifies genes and pathways for type 2 diabetes in human islets. Cell Metab (2012) 16(1):122-34. doi:10.1016/j.cmet.2012.06.006

Conflict of Interest Statement: The authors declare that the research was conducted in the absence of any commercial or financial relationships that could be construed as a potential conflict of interest.

Received: 29 May 2014; paper pending published: 06 June 2014; accepted: 26 June 2014; published online: 11 July 2014.

Citation: Ichimura A, Hara T and Hirasawa A (2014) Regulation of energy homeostasis via GPR120. Front. Endocrinol. 5:111. doi: 10.3389/fendo.2014.00111

This article was submitted to Diabetes, a section of the journal Frontiers in Endocrinology.

Copyright (c) 2014 Ichimura, Hara and Hirasawa. This is an open-access article distributed under the terms of the Creative Commons Attribution License (CC BY). The use, distribution or reproduction in other forums is permitted, provided the original author(s) or licensor are credited and that the original publication in this journal is cited, in accordance with accepted academic practice. No use, distribution or reproduction is permitted which does not comply with these terms. 